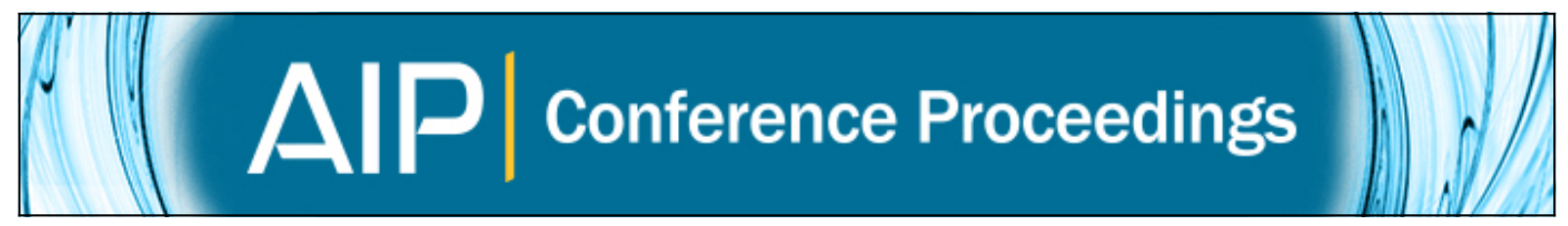

\title{
Regenerated silica gel as stationary phase on vacuum column chromatography to purify temulawak's extracts
}

Bambang Cahyono, Ratna Dewi Maduwu, Widayat, and Meiny Suzery

Citation: AIP Conference Proceedings 1699, 060022 (2015); doi: 10.1063/1.4938376

View online: http://dx.doi.org/10.1063/1.4938376

View Table of Contents: http://scitation.aip.org/content/aip/proceeding/aipcp/1699?ver=pdfcov

Published by the AIP Publishing

\section{Articles you may be interested in}

Signal analysis of NEMS sensors at the output of a chromatography column

AIP Conf. Proc. 1641, 329 (2015); 10.1063/1.4905995

Optimization of operating conditions for separation of non polar lipids fraction from soybean oil deodorizer distillate by regenerated silica gel

AIP Conf. Proc. 1586, 183 (2014); 10.1063/1.4866756

Carbon Nanotube Stationary Phase in a Microfabricated Column for High-Performance Gas Chromatography AIP Conf. Proc. 1137, 249 (2009); 10.1063/1.3156518

A new approach of the stationary axisymmetric vacuum $\mathrm{S}(\mathrm{A})$ solutions

J. Math. Phys. 44, 1679 (2003); 10.1063/1.1556191

Remanence curves of cobalt ferrite powders obtained by fractionation of a suspension through a silica gel column

J. Appl. Phys. 64, 5840 (1988); 10.1063/1.342225 


\title{
Regenerated Silica Gel as Stationary Phase on Vacuum Column Chromatography to Purify Temulawak's Extracts
}

\author{
Bambang Cahyono, Ratna Dewi Maduwu, Widayat and Meiny Suzery \\ Organic Chemistry Laboratory, Departement of Chemistry, Diponegoro University \\ Jln Prof. Soedharto SH, Tembalang, Semarang 50275, Tel / Fax: (024) 7460058 \\ Corresponding authors: bambang_cahyono@undip.ac.id
}

\begin{abstract}
Commercial silica gel only used once by many researchers and affected high cost for purification process, also less support the green chemistry program. This research focused in regeneration silica gel that used purification of temulawak's extracts (Curcuma xanthorrhiza Roxb) by vacuum column chromatography. Sample extracts (contains $10.1195 \pm 0.5971 \%$ of curcuminoids) was purified by vacuum column chromatography (pressure: $45 \mathrm{kPa}$, column: $100 \mathrm{~mm}$ on length and $16 \mathrm{~mm}$ on diameter). Ethanol $96 \%$ and acetone were compared as eluent. The amount of solvent and yield of curcuminoids used as indicator purification. The silica gel was regenerated with heating in $600^{\circ} \mathrm{C}$ for 8 hours The silica gels were analyzed by IR spectroscopy and X-ray diffraction. Furthermore, regenerated silica gel was used as the stationary phase in vacuum column chromatography under the same conditions with the previous purification. All the purification experiments were performed in three repetitions. Based on regression equation, $y=0.132 \mathrm{x}+0.0011 \quad\left(\mathrm{r}^{2}=0.9997\right)$ the yield of curcuminoids on purified products using ethanol as the eluent was improved $4.26 \%$ (to $14.3724 \pm 0.5749 \%$ ) and by acetone was improved 3,03\% (to $13.1450 \pm 0.6318 \%$ ). The IR spectrum of both silica gel showed the same vibration profile and also there were three crystallinity peaks missing on its X-ray diffraction. Regenerated silica gel has the same performance with new silica gel in purification of temulawak's extract: by ethanol has increased $4.08 \%(14.1947 \pm 0.7415 \%)$ and $2.93 \%(13.0447 \pm 0.4822)$ by acetone. In addition, all purification products showed similar TLC profiles. Purification using regenerated silica gel as the adsorbent on vacuum column chromatography has exactly same potential with the new silica gel.
\end{abstract}

\section{INTRODUCTION}

Column is one apparatus important in chromatography equipment that used separatior compounds. Commonly, the price of column is expensive but the column has operation time very long. If active compound in column un active, column can not used for separation in analysis use chromatography. The column can be modified or developed in accordance with the desired goals. Some equipments, such as preparative HPLC, is one example of development in Industry. The additional of a vacuum on column chromatography has advantages as higher elution rate also shortening the solute and adsorbent contact time[1]. This type of chromatography is still often used in education and research laboratory for the separation of extracts from natural products. Theoretically, this method can be developed in a larger scale.

One of the adsorbent that often used on vacuum column chromatography was silica gel. This material is widely used because it has very inert property, hydrophilic, has a thermal and high mechanical stability, and also relatively not swell in organic solvents[2]. Although this material is widely reported can be synthesized[3,4], but commercial silica gel still remain unreliable, although the price is quite high. Some researchers are still often use this adsorbent once. When it is done, itwill certainly requires a high cost when it should be applied to upper scale.

The objective of this research was to develop column regeneration for purification temulawak's extracts (Curcuma xanthorrhiza Roxb) and analysis with chromatography by using ethanol and acetone as eluent /mobile phase. 


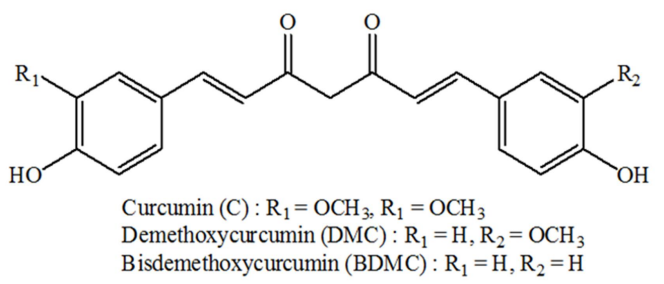

FIGURE 1. Molecular structure of Curcumin, Demethoxycurcumin and Bisdemethoxycurcumin[5]

\section{MATERIALS AND METHODS}

\section{Materials and Equipment}

Materials that used in this study are silica gel $\mathrm{GF} 60_{254}$ for thin layer chromatography from Merck was used as the stationary phase. Temulawak's extracts obtained from extraction temulawak's powder from Semarang, Central Java, using soxhlet. Standard curcumin which has high purity from Merck. Ethanol and acetone at technical grade as the eluent.

The equipment used in this process is column has $200 \mathrm{~mm}$ length (filled with silica gel $100 \mathrm{~mm}$ length) and $16 \mathrm{~mm}$ diameter. The vacuum pressure used was $45 \mathrm{kPa}$. Rotary vacuum evaporator from Buchi, analytical balance (Ohaus), furnace, oven, spectrophotometer UV-Vis (UV-1601 Shimadzu), spectrophotometer infrared (PerkinElmer Version 10.4.00), and X-ray diffraction.

\section{Experiment Procedure}

Temulawak's extract was been purified with adsorption desorption process with silica as adsorbent. 0.2010 gram of temulawak's extract mixed with silica gel with a ratio of 1: 1 and the sample become powder. For the column, $8 \mathrm{~g}$ silica gel that has been mixed with the eluent in a beaker glass, then stirred and poured into a column glass while the vacuum machine turned on to compress the column stationary phase (silica gel). The powder formed sample is poured slowly evenly inside the column and eluted with ethanol eluent until all the yellow color eluted.The amount of eluent used is recorded. The organic solvent on purified products is removed with a rotary vacuum evaporator. The weight of purification products recorded, which is furthermore the curcuminoids yield of this products were analyzed. Purification temulawak extracts by chromatography were done in three times.

The purification experiment also carried out with acetone eluent. The vacuum column chromatography conditions (length, diameter, pressure and the amount of silica gel) exactly the same as the previous experiments.

After the purification has done, the silica gel must be regenerated. Regeneration of silica gel is carried out by heating the adsorbent at a temperature of $600^{\circ} \mathrm{C}$ in furnace for eight hours. Various heating time $(1$ hour, 4 hours, 5 hours and 8 hours) were only done for one of the used silica gel.

\section{Analysis Methods}

Quantitative Analysis of Curcuminoids on Extracts done by using UV-vis Spectrophotometer. Standard curve obtained by preparing the standard curcumin solutions in some sort of concentrations, generally for a calibration curve used 7 variation of standard solutions, e.g. 1 ppm, 2 ppm, 3 ppm, 4 ppm, 5 ppm, 6 ppm and $7 \mathrm{ppm}$. Each concentrations were analyzed by using UV-Vis spectrophotometer at maximum wavelength $(425 \mathrm{~nm})$, then the absorbances of each concentrations obtained. Standard curve made by flowing the curcumin concentrations (ppm) vs the absorbances, hence the linier regression equation of the curve can be obtained. Furthermore, this equation will be further used for the determination of curcuminoid yield on temulawak's extract and for the purification products.

The curcuminoid yield can be determinated by dissolving the extract in technical ethanol, the diluted till the range detected by spectro equipment. Absorbance at the maximum wavelength $(425 \mathrm{~nm})$ was recorded 
and then converted into ppm using a linear equation. Curcuminoid percentage on extract or purification products were calculated based on the analyzed initial weight samples.

Then, regenerated silica gel was analyzed using infrared spectrophotometer and x-ray diffraction (XRD). FTIR analysis used was FT-IR Reflection Techniques. Silica gel as powder form transferred to the IR transparent $\mathrm{ZnSe}$ carrier. Xray diffraction was analyzed by XRD Shimadzu type 7000.using CuK $\alpha$ as probe. The measurement has been conducted $2 \theta$ from 10.4 to 86.6

\section{RESULTS AND DISCUSSION}

\section{Curcuminoid Analysis}

Sample of temulawak's extracts, dark brown colored, has a curcuminoid yield of $10.1195 \pm 0.5971 \%$. Curcuminoid percentage on temulawak's extracts obtained by using theuv-visible spectroscopy method. External standards (Figure 1) was used for analysis with curcumin as a standard. The absorbance vs. concentration standard curcumin produce a calibration curve with the equation $\mathrm{y}=0.132 \mathrm{x}+0.0011$, correlation coefficient close to $1\left(\mathrm{r}^{2}=0.9997\right)$

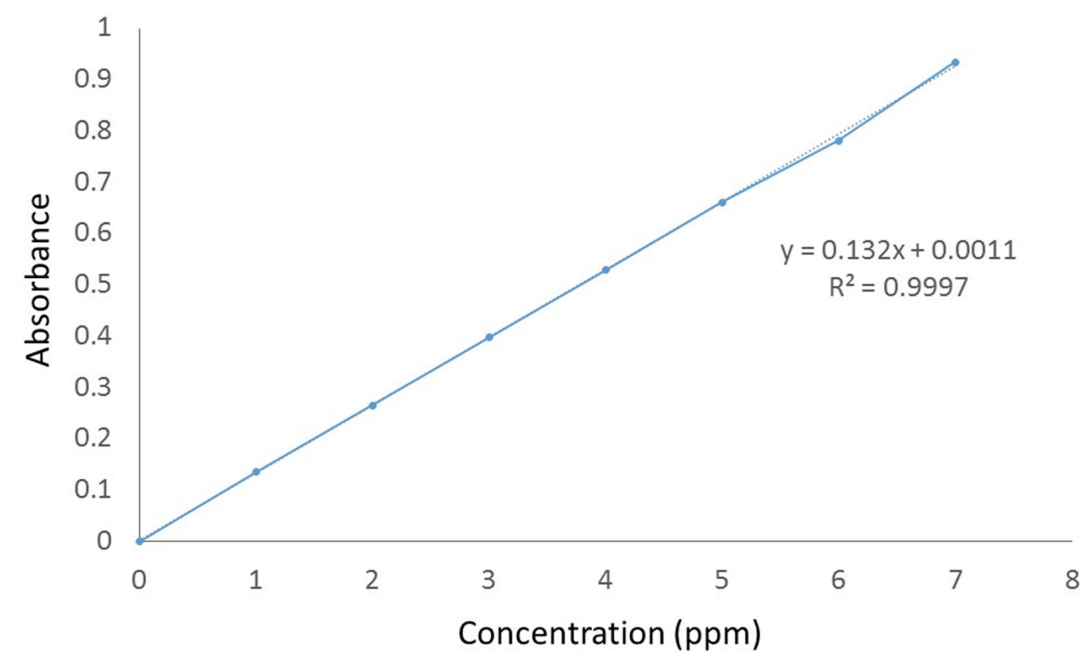

FIGURE 2. Calibration curve of curcumin

Although not specific to a single compound, UV-visible spectrophotometry method can be used for quantitative analysis of the total curcuminoid in Curcumasamples[6]. Three curcuminoid components, curcumin, bisdemethoxycurcumin and demethoxycurcumin, absorb at wavelengths around $425 \mathrm{~nm}[7,8]$. The adsoptivitas molar of three curcuminoid components were almost the same, ranging from 4.95 to $6.73 \times 10^{4}$ $\mathrm{Lcm}^{-1} \mathrm{~mol}^{-1}$. For these reasons, curcumin as the standard can be used to represent the sum of the three curcuminoid constituent in the analyzed samples[6-8]

\section{Purification of Temulawak's Extracts Using Vacuum Column Chromatography Results}

Silica gel is the most often stationary phase used to purify curcuminoid by column chromatography[5,9,10]. It is common known that silica gel is a weak acid, therefore, theoretically there is no chemical reaction with the compound to be purified (curcuminoids, also weakly acidic). The use of a single solvent in this study, acetone and ethanol, should be understood as both of these solvents are often used in pharmacy as a solvent[11-14]. Table 1 represents datas from temulawak's extract purification using vacuum column chromatography and new silica gel used as the stationary phase. 
TABLE 1. Data purified temulawak's extract using vacuum column chromatography and new silica gel used as the stationary phase

\begin{tabular}{cccc}
\hline Eluent & $\begin{array}{c}\text { \% product } \\
\text { average } \\
(\mathbf{w} / \mathbf{w})\end{array}$ & $\begin{array}{c}\text { Eluent volume } \\
\text { average }(\mathbf{m L})\end{array}$ & $\begin{array}{c}\text { Percentage of } \\
\text { purity } \\
\text { average* }(\%)\end{array}$ \\
\hline Acetone & $91.87 \pm 7.4056$ & $62.33 \pm 2.5166$ & $13.1450 \pm 0.6318$ \\
Ethanol & $88.45 \pm 2.5254$ & $60 \pm 3$ & $14.3724 \pm 0.5749$ \\
\hline
\end{tabular}

The weight yield, total eluent volume and the curcuminoid yield for each eluent were measured in three times repetitions. Based on Q-test for the three of repetition datas for each eluent, obtained at $\mathrm{P}=0.05$ that there are no outliers in the data or all datas can be received and statistically not found the error. The results of the t-test for both eluent,statistically showed no significant differences of the purity percentage average. From this vacuum column chromatography process the sample purity can be enhanced between $3.03 \%$ to $4.26 \%$.

\section{Analysis of New and Regenerated Silica Gel Using Infrared Spectrophotometer and X-ray Diffraction (XRD)}

It can be assumed that all organic compounds will thermally degraded into $\mathrm{CO}_{2}$ and $\mathrm{H}_{2} \mathrm{O}$ at $600^{\circ} \mathrm{C}[15]$. At that temperature, the structure of silica gel assumed will not change, therefore it can be reused as the new silica gel. Physically, the existence of an impurity in silica gel can be detected from the adsorbent color, white or not. Heated for 1 hour, 4 hours, 5 hours were still be seen the presence of black colored impurities in the silica gel. Silica gel will look clean after heating for 8 hours (Figure 3).

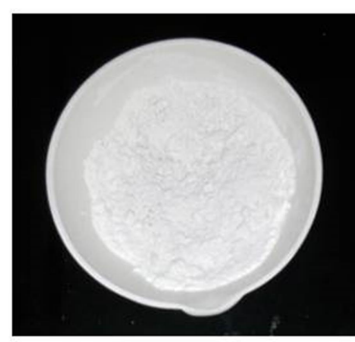

(A)

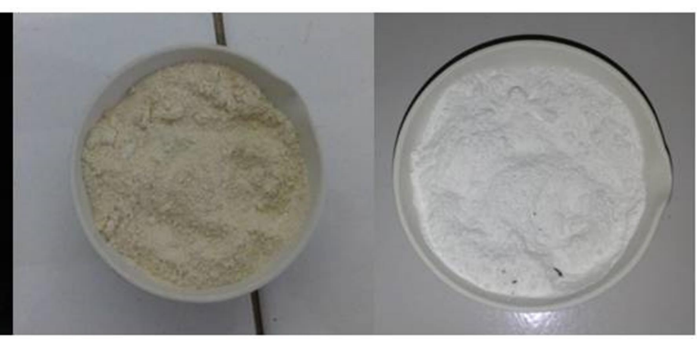

(B)
(C)

FiGURE 3. New silica gel (A), used silica gel (B) and regenerated silica gel (C)

Infrared spectrum of regenerated silica gel that heated on furnace at $600^{\circ} \mathrm{C}$ during 1 hour, 4 hours, 5 hours and 8 hours shown on Figure 4.The existence of foreign compounds in silica gel can be determined easily by comparing it with the infrared spectrum of the new silica gel. New silica gel here is silica gel that has been heated in the oven at $105^{\circ} \mathrm{C}$ for 2 hours to remove the water. A strong peak at wave number $1088 \mathrm{~cm}^{-1}$ as well as a narrow peak and width at $3411 \mathrm{~cm}^{-1}$ is the stretching vibration of Si-O and $\mathrm{OH}[16]$. 


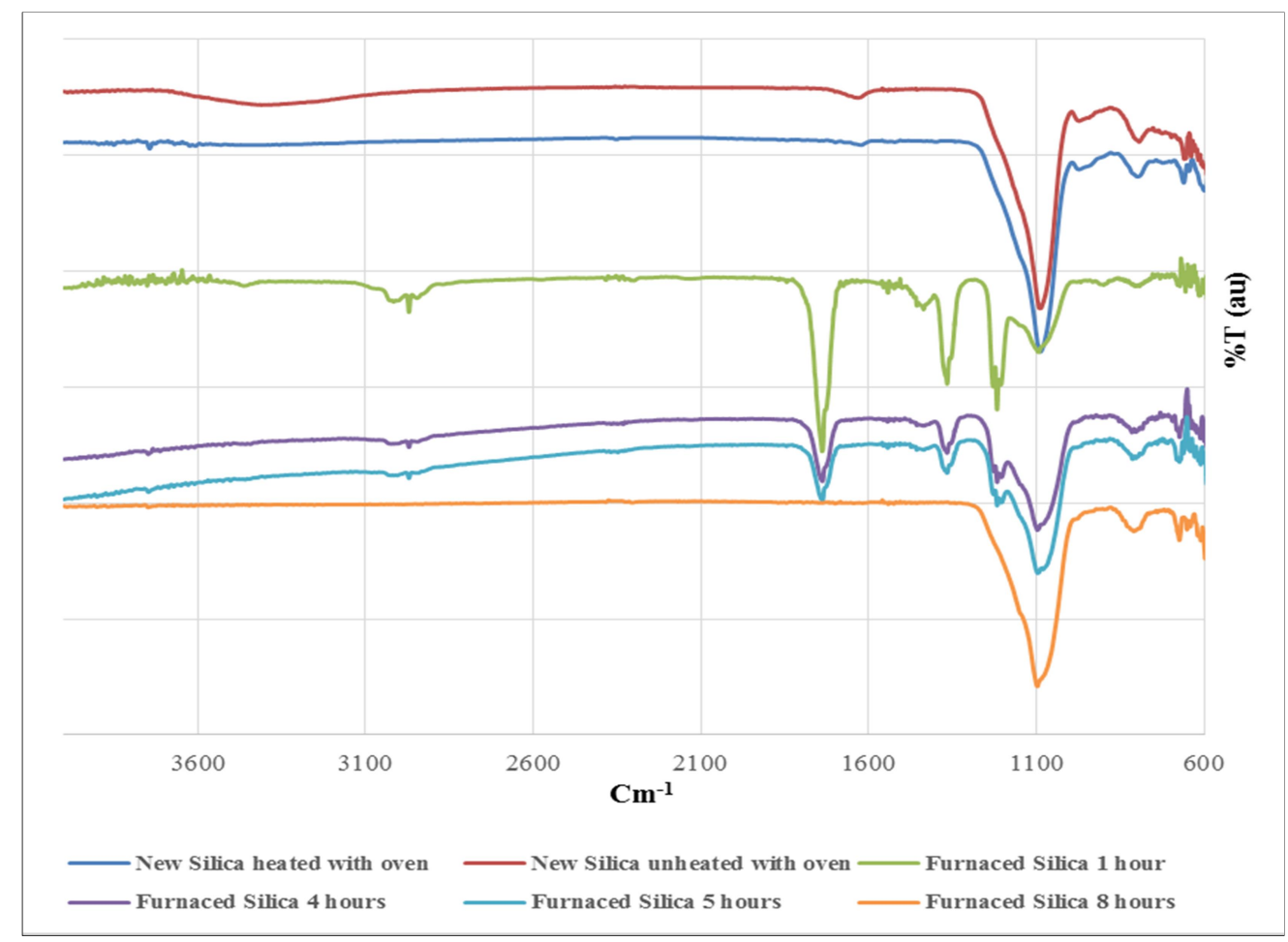

FIGURE 4. Spectrum of silica gel

Evaluated from the presence or the absence of impurities and also a new bond of regenerated silica gel, heating the adsorbent after using it on column was expected has the same composition with new silica gel. It should be added that X-ray diffraction pattern of the new and after furnaced for 8 hoursadsorbent was identics (Figure 5). From the results of the physical analysis, infrared and X-ray diffraction, we can expect the similarity potentialof the regeneratedsilica gel heating for 8 hours with the new silica gel on purification of temulawak's extracts.

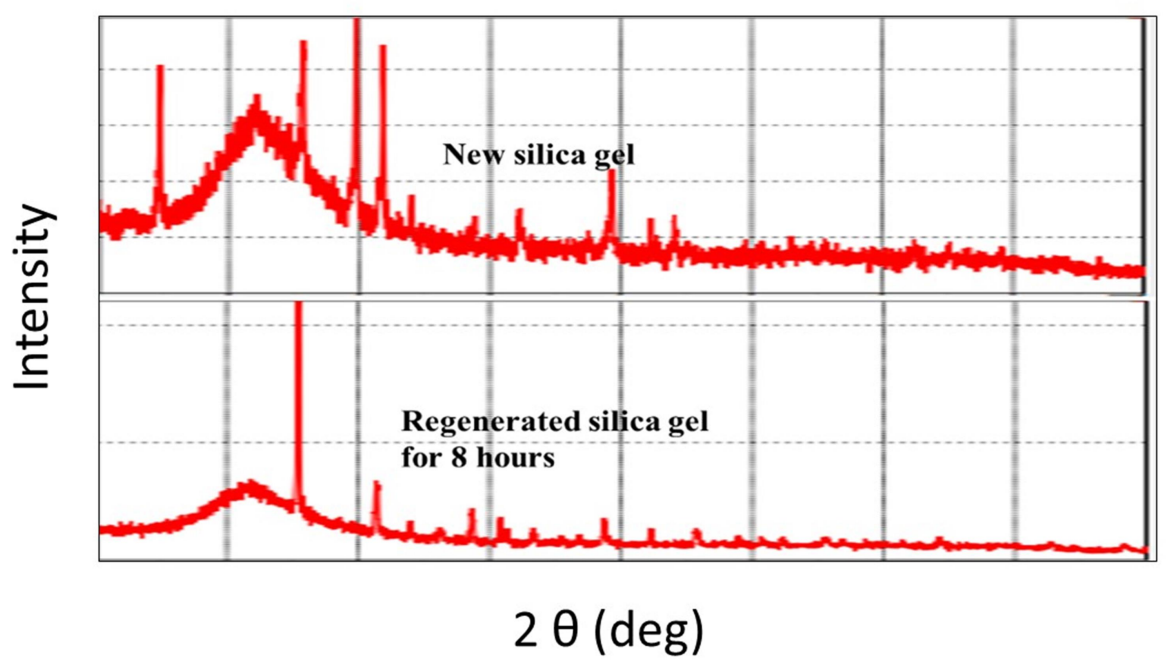

FIGURE 5. X-ray diffraction of silica gel 


\section{The Potential of Regenerated Silica Gel on Temulawak's Extract Purification}

Table 2 shows the datas of temulawak's extract purification using vacuum column chromatography with regenerated silica gel as the stationary phase. Statistically, the t-test at $\mathrm{P}=0.05$ indicates that there is no significant differences between the weight yield, the total volume of used eluent, and the purity percentage average result for each eluent using the regenerated silica gel compared to the new silica gel as the stationary phase.

TABLE 2. Data purified temulawak's extract using vacuum column chromatography and regenerated silica gel used as the stationary phase

\begin{tabular}{cccc}
\hline Eluent & $\begin{array}{c}\text { \% product } \\
\text { average } \\
\text { (w/w) }\end{array}$ & $\begin{array}{c}\text { Eluent } \\
\text { volume } \\
\text { average(mL) }\end{array}$ & $\begin{array}{c}\text { Percentage of } \\
\text { purity } \\
\text { average*(\%) }\end{array}$ \\
\hline Acetone & $86.45 \pm 3.8675$ & $64 \pm 1$ & $13.0447 \pm 0.4822$ \\
Ethanol & $85.88 \pm 1.5783$ & $60.67 \pm 1.5275$ & $14.1947 \pm 0.7415$ \\
\hline
\end{tabular}

In summary, Figure 6 shows a comparison of the purity percentage average result by vacuum column chromatography of both silica gel, new and regenerated, for each eluent. The comparison in Figure 6 shows that purification by vacuum column chromatography using the new and regenerated silica gel as the stationary phase has the same results: regenerated silica gel has the same ability with the new silica gelto purify temulawak's extracts.

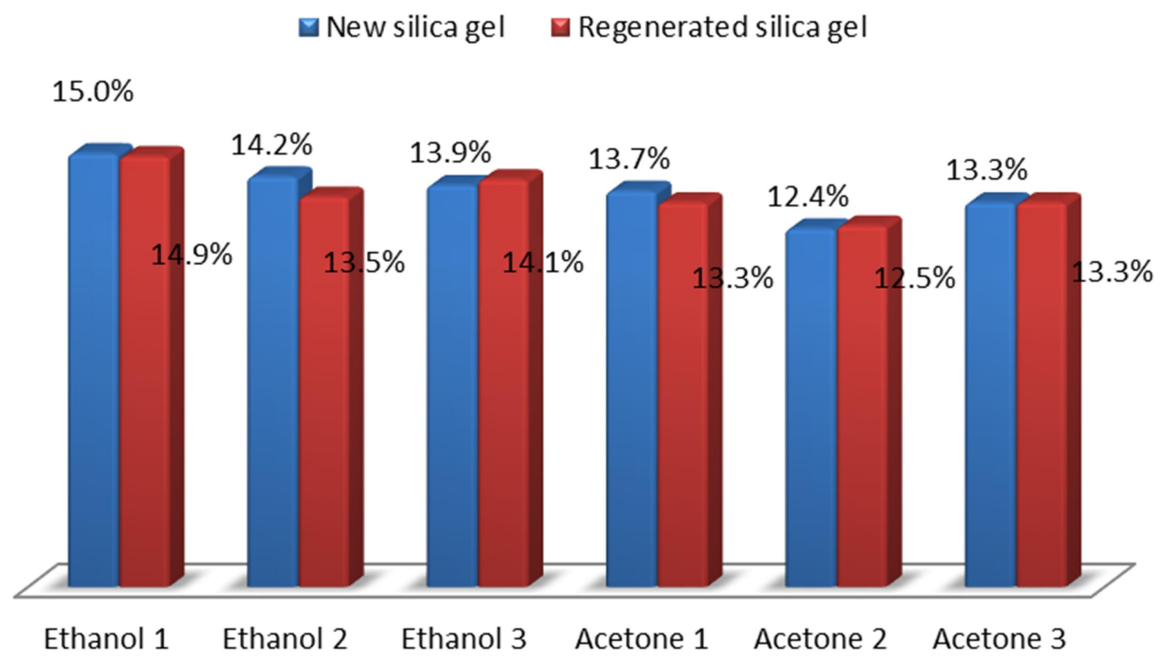

FIGURE 6. Comparison of the use of new silica gel and regenerated silica gel results on purity percentage average of purified products with eluent acetone and ethanol

\section{Thin Layer Chromatography (TLC) Analysis of The Purification Products}

This study was also carried out the analysis of Thin Layer Chromatography (TLC) to all purification products. Curcuminoid standard also placed on a TLC plate used as the comparison of curcuminoids components. Figure 7 shows the results of analysis by TLC along with Rf of each sample component. All the purification products contains three curcuminoids components where the $\mathrm{Rf}$ were the same as the $\mathrm{Rf}$ curcuminoids standard component. Therefore, it is known that all the purification products still contain three of curcuminoids components (curcumin, bisdemethoxycurcumin and demethoxycurcumin) and it signifies that the vacuum column chromatography can not be used to separate these three components. 


\begin{tabular}{|c|c|c|c|c|}
\hline \multirow{5}{*}{ 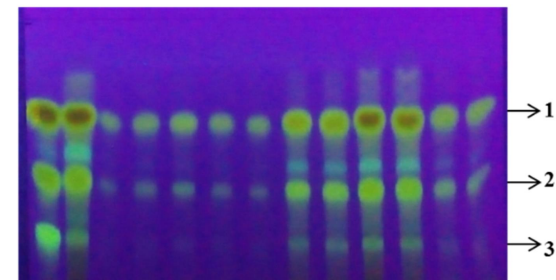 } & Sample & Spot 1 & Spot 2 & Spot 3 \\
\hline & $\mathrm{S}$ & 0.67 & 0.44 & 0.21 \\
\hline & EN1 & 0.66 & 0.43 & 0.23 \\
\hline & EN2 & 0.63 & 0.40 & 0.21 \\
\hline & EN3 & 0.63 & 0.40 & 0.21 \\
\hline \multirow[b]{2}{*}{ S EN1 EN2 EN3 EF1 EF2 EF3 AN1 AN2 AN3 AF1 AF2 AF3 } & $\mathrm{EF} 1$ & 0.63 & 0.40 & 0.21 \\
\hline & $\mathrm{EF} 2$ & 0.63 & 0.40 & 0.21 \\
\hline \multirow{7}{*}{$\begin{array}{l}\text { Description: } \\
\mathrm{S} \quad \text { (curcuminoid standard), ENx } \\
\text { (Ethanol eluent and new silica gel, } \\
\text { repetition to-x), EFx (Ethanol eluent } \\
\text { and furnaced silica gel, repetition to- } \\
\mathrm{x} \text {, ANx (Acetone eluent and new } \\
\text { silica gel, repetition to-x), AFx } \\
\text { (Acetone eluent and furnaced silica } \\
\text { gel, repetition to-x) }\end{array}$} & $\mathrm{EF} 3$ & 0.63 & 0.40 & 0.21 \\
\hline & AN1 & 0.63 & 0.37 & 0.19 \\
\hline & AN2 & 0.61 & 0.37 & 0.19 \\
\hline & AN3 & 0.63 & 0.37 & 0.19 \\
\hline & $\mathrm{AF} 1$ & 0.63 & 0.37 & 0.19 \\
\hline & $\mathrm{AF} 2$ & 0.63 & 0.37 & 0.19 \\
\hline & AF3 & 0.63 & 0.37 & 0.19 \\
\hline
\end{tabular}

FIGURE 7. TLC fingerprints of curcuminoids in the purification products(sample temulawak's extract). Stationary phase: Si-60GF 254 ; solvent system: $\mathrm{CHCl}_{3}$ : etOH (98:2); detection: UV 254

\section{CONCLUSIONS}

Has been evident from this research that the regenerated silica gel has the same capability with the new silica gel on purification of temulawak's extracts. Regeneration can be simply carried out by heating the used silica gel at temperature of $600^{\circ} \mathrm{C}$ for 8 hours. This experiment also provides a way for a more intensive course of a study, in particular to obtain data on when the used silica gel is no longer worthy to use. The application of vacuum column chromatography method with stationary phase regeneration such as this should be considered further for practical purposes, research or even a larger scale.

\section{Acknowledgement}

This research was supported by Fundamental Research, DIKTI, 2015

\section{REFERENCES}

[1] K. Hostettmann, M. Hostettmann, \& A. Marston, A., Preparative chromatography techniques : applications in natural product Springer-Verlag Berlin Heidelberg New York in (1998).

[2] J. Oscik, Adsorption, John Wiley and Sons, New York (1982).

[3] R. Febriyanti, T.A. Zaharah, \& N. Wahyuni, Jurnal Kimia Khatulistiwa, 3, 25-29. (2014)

[4] R. Patil, R. Dongre \& J. Meshram, IOSR Journal of Applied Chemistry (IOSR-JAC), 26-29 (2014)

[5] W. Pothitirat \& W. Gritsanapan, Mahidol University Journal of Pharmaceutical Sciences, 32 23-30 (2005)

[6] B. Cahyono, M.D.K. Huda \& L. Limantara. Reaktor, 13, 165-171 (2011)

[7] G.K. Jayaprakasha, J.M.L Rao \& K.K. Sakariah, Journal of Agricultural and Food Chemistry, 50, 3668-3672. (2002)

[8] L. Peret-Almeida, A.P.F. Cherubino, R,J. Alves, L. Dufosse \& M.B.A. Gloria, Food Research International, 38, 1039-1044. (2005)

[9] S. Revathy, S. Elumalai, M. Benny \& B. Antony, Journal of Experimental Sciences, 2, 21-25 (2011) 
[10] S.J. Kulkarni, K.N. Maske, M.P. Budre \& R.P. Mahajan, , International Journal of Pharmacology and Pharmaceutical Technology (IJPPT), 1: 2277-3436 2012

[11] W. Mangunwardoyo, Deasywaty \& T. Usia, International Journal of Basic and Applied Sciences, 12, 69-78 (2012)

[12] S. Hossain, G. Kader, F. Nikkon, \& T. Yeasmin, Asian Pacific Journal of Tropical Biomedicine, 2 125-127 (2012)

[13] L. Jun, Y. Liu, J.Q. Li, L.X. Chen, F. Zhao \& F. Qiu, Chinese Journal of Natural Medicines, 9 329333 (2011)

[14] F. Peng, Q. Tao, X. Wu, H. Dou, S. Spencer, C. Mang, L. Xu, L. Sun, Y. Zhao, H. Li, S. Zeng, G. Liu, \& X. Hao, Fitoterapia, 83 568-585 (2012).

[15] Kristianingrum, S., Prosiding Seminar Nasional Penelitian, Pendidikan dan Penerapan MIPA, Fakultas MIPA, Universitas Negeri Yogyakarta (2012.)

[16] K.H.S. Kung, \& M.B. McBride, Environ. Science Technology, 25 702-709 (1991). 